\title{
Household-Level Effects of Energy Insecurity on Welfare in Southern Africa: A Malawian Case Study
}

\author{
Fydess Khundi-Mkombaa,d*, Akshay Kumar Saha ${ }^{\mathrm{b}}$, Umaru Garba Walic \\ ${ }^{a}$ University of Rwanda, College of Science \& Technology, African Center of Excellency Energy for Sustainable Development, Rwanda \\ ${ }^{b}$ University of KwaZulu-Natal, School of Engineering, Howard College Campus, Durban, South Africa \\ cUniversity of Rwanda, School of Engineering, College of Science \& Technology, Rwanda \\ dLilongwe University of Agriculture \& Natural Resources, Department of Applied \& Agricultural Economics, Malawi
}

\begin{abstract}
The debate of energy security has, over the past decades, centered on supply factors within the energy policy framework in the public policy discourse. Much more empirical evidence is required to fully understand the household-level effects of energy security on development outcomes. This paper explores the characteristics of the households that face energy insecurity and also analyze the effects of energy insecurity on household welfare using the recent data from the Malawi Fourth Integrated Household Survey(IHS4) 20162017. Overall, $42.58 \%$ of Malawian households were found to be energy insecure and the study findings show that the energy insecure were a heterogenous group compared to the energy secure. The heterogeneity exist because of differences in demographics (likely to be advanced in age, likely to be females, less likely to have a household head with formal education); socioeconomic status (likely to be poor, had low wealth levels); geography (likely to be rural dwellers in the central and southern parts of Malawi); housing and dwelling status (less likely to be renters, less likely to be found in permanent or semi-permanent buildings that have iron sheets and cement floor). Additional results from econometric analysis showed that energy insecure households reduced their food consumption by $2.3 \%$ for each $1 \%$ unit increase in the share of the energy costs in their total household budget. Similarly, on the education outcome, the energy insecure households reduced their education expenditure by $3.6 \%$ for each $1 \%$ unit increase in the share of the energy costs over the total household expenditure. These findings show that energy security plays a key role towards improvement of household welfare in general as this might have short term and long-term negative implications on human capital development.
\end{abstract}

Keywords: Energy insecurity; household welfare; Malawi; Southern Africa

Article History: Received: $6^{\text {th }}$ Sept 2020; Revised: 26 th Oct 2020; Accepted: 29th Oct 2020; Available online: $1^{\text {st }}$ Nov 2020

How to Cite This Article: Mkomba-Khundi, F., Saha, A.K., and Wali,U.G. (2021) Household-level Effects of Energy Insecurity on Welfare in Southern Africa: A Malawian Case Study. International Journal of Renewable Energy Development, 10(1), 105-118

https://doi.org/10.14710/ijred.2021.33234

\section{Introduction}

The total installed generation capacity for grid electricity in Malawi (around 361MW) is not adequate enough to meet the current demand for both industrial and domestic use (over $1000 \mathrm{MW}$ ), making it one of the energy -stressed countries in the Southern African region (GoM, 2018; GoM, 2017). For instance, the in-country study confirmed low uptake of Liquid Petroleum Gas (LPG) as a cooking fuel, with only $2 \%$ of the urban population that was monitored using the fuel despite being the most costefficient cooking fuel (Practical Action, 2017). So far, there is scanty literature in the country to show how the energy burdens are impacting household welfare amidst climate change, population growth and in view of growing urbanization due to secondary towns and cities. A study by Maganga et al. (2015) revealed that location of residence, education level of household head, income, and age of household head were major significant factors in determining the probability of household's choice of cooking fuels. However, their study only focused on the non-price factors that determine the probability of household cooking energy choices but left out the other important aspect of energy use patterns such as home lighting. But how many households are energy insecure and to what extent does energy insecurity affect household welfare in Malawi to achieve the sustainable development goals number 7 and 12 which demand inclusive access to clean energy for all and responsible consumption and production respectively? This remains a major public policy research question that demands more empirical research.

This study explored the characteristics and assessed the effects of energy insecurity on household welfare in a developing country context. It used data from the Malawi Fourth Integrated Household Survey (IHS4) 2016-2017, which is part of the World Bank's Living Standards

\footnotetext{
${ }^{*}$ Corresponding author: fkhundi@gmail.com
} 
Measurement Survey (NSO, 2017). Specifically, the study examined the household welfare (food consumption and education expenditures) of Malawian households to understand which among them were burdened and greatly affected by high energy expenses to explore prospects for renewable energy sources such as solar to ensure energy security at household level (Ezema et al., 2016; Ahmad \& Byrd, 2013). Therefore, this paper is empirically relevant in such a way that it provides insights into which type of households are highly burdened with energy costs from poverty and education policy perspectives. It is timely and points to policy gaps especially in this era of Covid 19 pandemic and calls for policy measures to promote diffusion and adoption of modern commercial fuels such as LPG, solar or any of other renewables to diversify energy sources thereby increasing energy security. Renewable technologies such as solar photovoltaics, windmills, LPGs, and micro hydro power stations are associated with improved range of socio-economic benefits leading to reduced environmental pollution as well as opportunity costs leading to improved development outcomes for women and children in the long run (Shoaib \& Ariaratnam, 2016). The major setback for these modern fuel sources lies in the initial start-up costs for connections in case of grid electricity and equipment, and stoves for LPG as such most poor households are not able to adopt. Household decision making process on energy consumption and fuel choices is complex since it is hinged on a wide array of factors encompassing economical, technical, social and cultural reasons which vary depending on the study context (LV et al., 2018).

Taking the case of Malawi, its annual urbanization rate increased from 3.7 to 3.9 percent with around 2.8 million people living in urban areas between the years 1998 to 2008 and is classified to be modest compared to other African countries (World Bank, 2016). In addition, the World Bank report further shows that Malawi had moderate annual net migration inflow of roughly 14,000 working-age migrants that relocated to cities and towns from the period of 2006 to 2010 that resulted to modest urban population growth. This rate and pace of urbanization presents a golden opportunity to Malawi to capitalize on the multiplier effects that come with urban agglomeration especially in the promotion of renewable energies such as LPG and Solar and other clean energy sources to reduce energy burdens in homes. So far, the four Malawian cities (Lilongwe, Zomba, Mzuzu, Blantyre) contributed 33 percent to the national growth domestic product (GDP) despite having a lower percentage towards the total population which is around 13 percent. On the contrary, the rural parts consist of $85 \%$ of the Malawian population but offer only 62 percent towards the national GDP (Manda, 2013). In addition, secondary towns inhabit almost 3 percent of the total population with a 6 percent contribution to national GDP which is remarkable. As of 2018, the Malawian population had increased from $13,077,160$ in 2008 to $17,563,749$ in 2018 with 16 percent of the population residing in the urban areas (NSO, 2019). This simply shows that the urban economy has a lot to offer in terms of making significant impact towards the national development growth agenda thereby realizing sustainable development goal outcomes.

On the other hand, the trend of growing secondary towns has forced rural households in Malawi to live in close proximity with urban households in smaller towns. This has caused some rural households to adapt to land scarcity and deforestation as a result of rural-rural and urban-rural migration patterns (Stringer et al., 2009). So, what is pertinent in this research study is to get understanding in terms of how energy security is shaped by this pattern of urbanization and migration which lead to both direct and indirect influences on household welfare and decision-making processes for both urban and rural residents (Tchereni, 2014; Chikhungu et al., 2014).

The existing literature highlights multiple alternative metrics and several dimensions that are used to capture the extent and nature of the energy burden problems globally as conceptualized in Fig.1. A summary of all key literature regarding these alternative metrics and dimensions to capture energy burden problems is presented in Table 1.

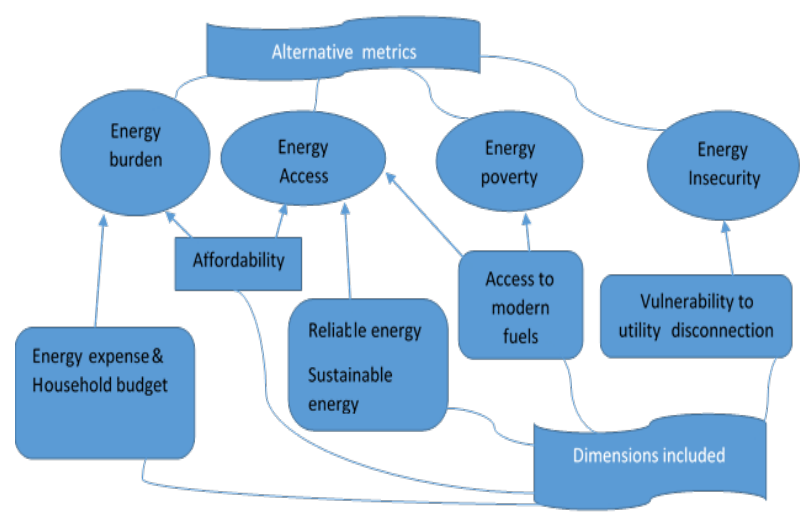

Fig 1. Scope of energy burden and related definitions.

Source: Adapted from Brown et al. (2020).

At international level, energy poverty has simply been referred to as lack of access to energy services.Some scholars over the past decades have conceptualized energy poverty as a commodity basket to satisfy basic home energy requirements such as lighting, cooking and entertainment plus other special energy needs and is usually understood arbitrarily (Khandker et al., 2012). To date, there is no universal consensus regarding this "energy poverty construct" and still varies depending on culture, climate and country contexts (Pachauri \& Spreng, 2011\& 2004; Bilal \& Szirmai, 2010; Foster et al., 2000). Recently, the energy poverty concept has evolved into several definitions by different scholars making it possible to be investigated in both developed and developing countries since it affects quality of life and welfare (Maxim et al., 2016; Pye et al.,2015). Nussbaumer et al. (2012) formulated a Multidimensional Energy Poverty Index (MEPI) that allows for a number of energy components that relates to cooking, lighting entertainment and communication. One of the limitations of this index is that it only concentrates on specified segment of population especially those with inadequate modern energy access and heavy users of dirty fuels such as wood and kerosene (Phoumin, 2019a). Generally, weighing and aggregation to construct the indices (i.e. energy poverty index, energy development index, MEPI) still remain a challenge. For instance, the World Bank Multiplier Framework (MTF) Index is highly contested because it is indeterminate why equal weights are assigned to different household energy usage i.e. productive use having same weight as community energy usage (Culver, 2017; Grohet al.,2016; Mirza \& Szirmai, 2010). Barnes et al. (2010) measured 
energy poverty in a more intuitive way using a 10\% energy share cut off point threshold as a way how it may affect other household basic necessities such as food. However, there are still outstanding issues that need to be addressed to have a universal consensus towards energy poverty of which some include need for a proper rating scale so that income composition and selected threshold properly guide the targeted study population (Moore, 2012). Furthermore, energy poverty is also highly linked to and dependent on non-economic factors such as culture and individual privacy coupled with both temporal and space dynamic dimensions (Thomson et al., 2017). Energy access terminology has been commonly used by international agencies especially the United Nations who adopted Sustainable Cities and Communities Goal (SDG 11) and Sustainable Development Goal 7 (SDG7) (UNDP, 2017; Barnes et al., 2010). SDG 11 aims at ensuring provision of adequate and affordable utility basic services whilst the SDG 7 emphasizes at provision of affordable, reliable, sustainable and modern energy services to all by 2030.

Regarding household energy burden, Colton (2011) classified "energy poor households" as those households having a share of energy costs of greater than $6 \%$ to their total income. For this scholar, the reference point was that a household was supposed to spend less than $30 \%$ of its budget on housing cost whilst expenditure on utilities is supposed to be less than 20\%. Furthermore, other scholars in United States of America (USA) are still proposing a variety of thresholds. For instance, Cook \& Shah (2018a) classified energy stressed households as those with energy burden of about 4 to 7\%; energyburdened households as those having energy burden of about 7 to $10 \%$ and lastly the energy-impoverished households were households that had energy burdens of more than $10 \%$. In other words, energy burden refers to the share of household income that is spent on the energy costs and is usually the largest among the poor (Drehobl \& Ross, 2016).

The other new construct by Berry et al. (2018) defines "energy insecurity" as a situation whereby a household is not sure of possibility of being able to pay its utility bills, that may lead to temporary or permanent utility disconnection towards the energy services. Elnakat et al. (2016) and Ross et al. (2016) noted that energy security incidence varies depending on study context. The International Energy Agency (IEA) defines energy security as the uninterrupted availability of energy sources at an affordable price (Ayoo 2020). Since there are many definitions, for consistency purpose, this study adopted the definition of household energy insecurity as spending greater than $10 \%$ of household income on energy expenses (Phoumin, 2019; Hernandez et al.,2016; Hernandez et al.,2014). In other words, this paper adopted the approach of using 10\% threshold of household energy expenditure as an energy insecurity cut-off point. However, this paper did not employ the other approach of using the minimum $600 \mathrm{KWh} /$ year household electricity consumption threshold as was the case in the Cambodia study by Phoumin (2019) or 2125 KWh in the Guatemala study by Foster et al. (2000) to avoid restricting the analysis to grid connected households.

Despite much interest in energy security, there is limited empirical research documenting household-level effects of energy insecurity across different socio-economic groups especially in a developing country context using large sample size from the ongoing World Bank Living standards survey datasets that are making data accessible and open to both scholars and development practitioners. To the knowledge of the authors, this is one of the few energy studies that examine household welfare effects of energy insecurity within the developing country contexts using large sample data. As such, this study fills the existing gap in the literature and justifies the need to find innovative ways of improving access and affordability of both clean and energy efficient technologies to reduce disparities between the rich and the poor in developing economies.

Thus, this article contributes to the public policy discussions concerning energy burdens and equity under household renewable energy transitions by ensuring that the voice of the poor is heard in energy decision-making process as a basic right for all. The following were the guiding research questions for this study:

1) Which households face energy insecurity in Malawi?

2) To what extent does energy insecurity incidence affect household welfare?

3) What are some of the policy lessons drawn from the research study?

These research questions were explored by paying particular attention to differences in locations (urban versus rural households) and other socio-economic characteristics to highlight the disproportionate burdens borne by vulnerable societies when meeting energy needs in their homes. The results confirm and reveal that energy insecurity heavily affected the welfare of households more especially on the education consumption with slightly large magnitude compared to the food consumption outcome. Understanding welfare effects of energy insecurity at household level in a developing country context, particularly from an energy burden perspective, is critical so that public policy design is fully informed in the Global South.

\section{Materials and Methods}

\subsection{Data source and description}

This study utilized secondary data from Malawi Integrated Household Survey (IHS4) 2016-2017. The survey was conducted by the National Statistical Office (NSO) in Malawi in collaboration with the World Bank. The datasets are publicly available and published by the World Bank as part of its Living Standards Measurement Study (LSMS) programme (NSO, 2018). The survey covers a nationally representative sample designed to provide information on the various aspects of household welfare in Malawi. The survey collected information from a sample comprising of 12,447 households but after data cleaning, this study only used 12,439 households that had all key variables for analysis. The sample was statistically designed to be representative at both national and district as well as urban and rural levels, enabling the provision of reliable estimates for these levels. The sampling involves a stratified two-stage sample design. The primary sampling units (PSUs) selected at the first stage are the census enumeration areas (EAs) as defined in the 2008 Malawi Population and Housing Census.The EAs have an average of about 235 households each. A total of 768 EAs are selected across the country. 


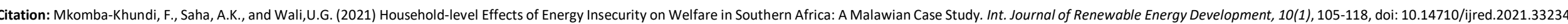
P a g e $\mid 108$

Table 1

Literature reviewed for the study

Scholar name Theme

Khan

Mirza Bilal and Energy poverty

Szirmai (2010)

Foster et al. (2000) Energy poverty

Maxim et al.(2016); $\quad$ Energy poverty

Pye et al. (2015)

Barnes et al. (2010)

Moore (2012)

Energy poverty

Energy poverty

$\begin{array}{ll}\text { Nussbaumer } \text { et al. } & \text { /fuel poverty } \\ \text { Energy poverty }\end{array}$

(2012)

Thomson et al. Energy poverty

(2017)

Phoumin (2019b)

Culver (2017)

Pachauri \& Spreng

(2004)

Barnes et al. 2010

Energy poverty

Energy poverty

Energy access/

Energy

Energy access

Elnakat et al. (2016) Energy access

Groh et al. (2016)

UNDP (2017)

Colton (2011)

Energy access

Energy access

Cook \& Shah Energy burden

(2018a)

Drehobl and Ross Energy burde

Ross et al. (2016)

Berry et al. (2018)

Energy burden

Energy

insecurity

Ayoo (2020)

Energy
insecurity

Hernandez et al. Energy

et al. (2014)

Energy

\section{Geographical context \& period of analysis}

ross sectional data from a comprehensive 2005 Used energy poverty survey data of 2009 in Pakistan

Used 1998/99 income expenditure survey data in Guatemala, Latin America

Used data from Eurostat on different proxy variables (i.e tenure status, income, well-being \& material deprivation) in the year 2016

Based on cross section data from a 2004 survey of some 2300 households in rural Bangladesh

European measure especially deinitions based on common

Used DHS data of 1997-2003; 2004-2009 from

Utilized pan-European datasets to do a comparative study of energy poverty across the EU

Used 2015 Cambodia socio economic survey dataset

A 2017 critical review paper on different metrics of energy

tion study on energy use \& energy access in relation to poverty

A review on modern energy services for the poor especially
World Bank portfolio projects approved from 2000 to 2008 financial year

Utilized socioeconomic and demographic data at Zip code level in San Antonio service area for a period of 48 months (2009-2014)

2016 case study of Bangladesh which utilized household survey data

countries to country datasets and statistics of different

Used 3-year (2007-2009) average American comm survey data published by U.S. Census Bureau

A 2018 Feasibility study for Colorado residents to reduce energy burden with solar in North America

Used US census bureau 2011 and 2013 American housing Used 2016

Used U.S Energy Information administration, 2015 residential energy consumption survey dataset

Used global statistics on production and consumption of oil from 1980 to 2017

Used 2011 American community survey data

Used 2015 Cambodia socio economic survey dataset

\section{Method/Approach}

mployed a demand-based approach to defining energy poverty

Constructed a composite index to measure degree of energy poverty

Employed poverty measurement techniques such as poverty head count, FGT

Proposed a compound energy poverty indicator (CEPI) as a standardized measure

Used instrumental variable regression to estimate welfare mpacts of household energy use

also used Pret standard approach matter

Proposed a multidimensional energy poverty index

Presented statistical options for monitoring energy poverty Employed two stage least square

Highlighted both binary and composite metrics of energy poverty

energy use-access matrix by combining two pproaches

Defined energy access as relating to both physical proximity to energy infrastructure \& to policies \& frameworks supportin ransition to better, reliable \& more efficient use of electricity $\&$ modern fuels

Tested statistical significance of relationships between variables such as income, gender, occupancy, total energy, per

Compared binary indicators of energy access compared to the

Pesers indicators

Calculated the affordability gap based on income and household energy bills in 5 primary areas (tenancy status, housing unit size, heating \& cooling degree days, household size, heating fuel mix, energy use intensities

Evaluated low income energy burden by using housing and fue type \& Photovoltaics technical \& market potential

Calculated energy burden values for 48 of the largest US citie Cand specitic hous

centage of household income spent on energy bills

Explored the characteristics of energy insecure households by capturing occurrence, severity and frequency of energy

insecure events lasting anywhere from few weeks to 1 year

Employed some indicators to assess changes in energy security such as promotion of energy efficiency, modernizing

Enmloyed multivariate statistical analysis using multinomial logistic regression

Used multiple regression analysis

\section{Energy burden problem tackled}

Focused on correlation of energy poverty and income poverty

Analyzed characteristics and consequences of different energy mixes ween the rich and the poor

ge fuel costs to measure energy povert

Assessed energy poverty across all $28 \mathrm{EU}$ member states

Reviewed energy poverty approaches and examined role of moder energy in poverty alleviation

finition \& argues based on budget standar approach to categorize vulnerable households

Examined incidence and intensity of energy poverty using 6 indicators (modern cooking, indoor pollution, electricity access etc.)

An exposition energy poverty measurement approaches via of vulnerability thinking

xamined impacts of energy poverty on health, education and earning

Reviewed different metrics of energy poverty

Measured energy use \& energy access in relation to poverty

Compiled an up to date database on energy access related assistance \& patterns of energy access related assistance

Investigated influence of socioeconomic \& demographics on residentia energy utilization patterns at ZIP code level

Evaluated the World Bank's multi-tier framework to measure electricity

Highlights energy access in form of sustainable development goal 7

Defined home energy affordability gap in form of a bill, and a bill was considered "afford

Analyzed energy burden and Photovoltaics potential of

Provided a snapshot of energy burdens in cities across the USA.

Examined residential energy affordability in rural and small-town America and identified energy efficiency as a strategy for reducin ergy burdens

Examined multidimensional nature of energy security

Demonstrated housing hardship and energy insecurity among the native born and immigrant low income families with children

Analysed the impact of Energy insecurity on household welfare in 
In each district, a minimum of 24 EAs are interviewed while in each EA a total of 16 households are interviewed. Dependent and Independent variables: The key dependent variables of interest were food consumption and education expenditure variables as "proxy" for household welfare. The food consumption was measured as log annual household food consumption whilst education outcome was measured as log annual household education expenditure to reduce the effects of outliers that can pose heteroskedasticity problem. NSO report provides detailed information on calculation of the consumption variables to get the annual total household expenditures (NSO, 2018).The key independent variable of interest was energy insecurity. This was constructed from the probabilities that were highlighted under the empirical model framework in the next section. The selection of the independent variables that affect welfare and their inclusion in the regression analysis was informed based on the previous studies (Nguyen \& Nguyen, 2019; Phoumin, 2019; Hernandez et al., 2016; Castro-Sitiriche \& Ozik, 2014).

\subsection{Empirical model}

Statistically and economically, a Cobb-Douglas type economic welfare function (Fang, 2011) was estimated in this paper and the empirics date back to the economic theoretic works of Cobb and Douglas in 1928 and later Handsaker and Douglas plus Williams (William, 1945; Handsaker \& Douglas, 1937; Cobb \&m Douglas, 1928). Therefore, to measure influence of energy insecurity on household welfare outcomes, the study employed multiple regression analysis which is very sound and appropriate whenever the dependent variables are all continuous variables (Mango et al.,2018; Lopez-Espin et al., 2012). Following Phoumin (2019) and Ross et al. (2018), to get a thorough understanding on how much households are energy-burdened, the hypothesis of assessing how household energy insecurity incidence affects household welfare (food consumption and education consumption outcomes) is formulated as follows:

$$
\begin{aligned}
& \mathrm{P}\left(E_{i}=1\right) \\
& =\mathrm{Q}\left(E_{i}=S E>10 \%\right) \text { if household is not energy secure; } \\
& \quad \mathrm{P}\left(E_{i}=0\right) \text { if otherwise }
\end{aligned}
$$

Where SE is the share of energy expenditure to the total household expenditure, Q(.) is an indicator function that may take values 1 if the expression in the brackets holds and zero otherwise. It depicts that when Q(.) takes the value of 1 , then that household is energy insecure. Therefore, mathematically, household incidence of energy insecurity (EI) is formulated as follows:

$$
E I_{i}=\frac{1}{N} \sum_{i=1}^{n}\left[Q\left(E_{i}=S E>10 \%\right)\right]
$$

Now to link the household energy insecurity incidence to household welfare (food consumption and education expenditure outcomes), two structural equations were formulated as follows:

$W_{i}=\phi_{0}+\phi_{1} E I_{i}+\phi_{i} X_{i}+u_{i}$
Table 2

Regression diagnostic test on multi-collinearity

\begin{tabular}{lcl}
\hline Variable & VIF & 1/VIF \\
\hline Marital status & 2.46 & 0.4064 \\
Log per capita household annual & 2.30 & 0.4351 \\
consumption & & \\
Gender of Household head & 2.23 & 0.4493 \\
Grid electricity access & 2.02 & 0.4943 \\
Urban location & 2.00 & 0.4992 \\
Tenancy & 1.99 & 0.5031 \\
Main source for drinking water & 1.93 & 0.5171 \\
Household size & 1.68 & 0.5963 \\
Owner occupant & 1.68 & 0.5968 \\
Plot ownership & 1.54 & 0.6482 \\
Household head with some education & 1.28 & 0.7823 \\
Household energy insecurity status & 1.26 & 0.7958 \\
Livestock ownership & 1.17 & 0.8528 \\
Age of household head & 1.13 & 0.8844 \\
Mean VIF & 1.76 & \\
\hline Source: Authors' estimation from Malawi IHS4 (2016/17) & \\
\end{tabular}

$W_{i}=\gamma_{0}+\gamma_{1} S E_{i}+\gamma_{i} X_{i}+\varepsilon_{i}$

Where $W_{i}$ is household welfare which is the dependent variable depicting food consumption and education consumption outcomes in both equations. The first structural equation (3) captures household energy insecurity incidence $\left(E I_{i}\right)$ as part of the regressors to assess the direct effect on household welfare. In the second structural equation (4), the share of the energy expenditure $\left(S E_{i}\right)$ was used to assess the magnitude of the effect of the energy insecurity incidence. Finally, $X_{i}$ is a vector of socio-economic factors (such as education, age, household size and others) that also affect household welfare whilst; $u_{i}$ and $\varepsilon_{i}$ are error terms and are normally distributed which implies $u_{i}$ or $_{i} \sim \mathrm{N}(0,1)$ and $\phi, \gamma$ were parameters that were estimated using ordinary least squares (OLS) regression models because the two dependent variables were continuous in this case. Again, to address the heteroscedasticity problem the two dependent variables were transformed into natural logarithm form.

The multiple regression was used to test the study's existing hypotheses. As such, multi-collinearity test was conducted and results showed that the Variance Inflation Factors (VIF) for the covariates were within the allowable limit of below 10 (refer Table 2) and this implies that there was no multi-collinearity problem with the data (Zou \& Luo, 2019; Phoumin, 2019). Additionally, the robustness standard errors correction techniques such as using "the option robust" in STATA 14 statistical software was used to reduce inflation of the estimated coefficients more and T-statistics.

\section{Results and Discussion}

\subsection{What are characteristics of households that are facing EI?}

Recalling the definition of energy insecurity in the methodology section, this study found that $42.58 \%$ of the 
households were energy insecure. Differences in households faced with energy insecurity were defined by several factors: (a) energy choices and electricity status, (b) geographic variables (regional or district location) (c) demographic variables and (d) housing tenure, dwelling status and asset variables. Firstly, the energy insecure households are differentiated by energy sources for lighting and cooking (Table 3). Table 3 compares the means of the lighting and cooking fuel choices for the sample households based on their energy insecurity status. The significant $\mathrm{P}$-values show that there were some differences between the two groups. The main household energy sources for lighting that were reported were gas, grid electricity, kerosene, candles, torches, fuel wood and other fuels such as grass as indicated in Table 3 . On the other hand, the main household energy sources for cooking were gas, electricity, kerosene, charcoal, fuel wood and other fuels such as crop residues and saw dust. The significant P-values showed that the energy use patterns of the two groups were unbalanced with respect to accessibility of modern energy services infrastructure. The result showed that the energy insecure tend to use kerosene, fuel wood as their lighting fuels more than the energy secure. Regarding cooking fuels, the energy insecure tend to use fuel wood more compared to the energy secure in relative terms.

Regarding the grid electricity access and frequency of blackouts, tree maps visualization techniques were employed using Microsoft Excel software as a representation of hierarchical information to see the differences between the two groups in the year 2016/17 (Aberman et al., 2018; Long et al., 2017). The differences are shown graphically in Fig 2 for grid electricity access for the whole sample and in Fig 3 frequency of blackouts for the sub-sample of the grid connected households. These findings resonate with Jessel et al. (2019) who described energy insecurity as either a long-term issue that can arise from a consistent inability to access adequate energy to meet household needs or a short-term issue that tends to arise from infrastructural , maintenance, environmental or other external sources that disrupt access to energy sources.

Table 3

Mean comparison for lighting and cooking fuel variables

\begin{tabular}{lcc}
\multirow{2}{*}{\multicolumn{1}{c}{ Variable }} & \multicolumn{2}{c}{ Difference in mean } \\
\cline { 2 - 3 } & $\begin{array}{c}\text { (energy -secure) } \\
\text { (energy-insecure) }\end{array}$ & $\begin{array}{c}\text { p- value } \\
\text { of diff. }\end{array}$ \\
\hline Lighting fuel choices & 0.063 & 0.000 \\
Gas\& grid electricity (1=yes) & -0.029 & 0.000 \\
Kerosene (1=yes) & -0.014 & 0.000 \\
Fuel wood (1=yes) & 0.002 & 0.766 \\
Torches (1 = yes) & -0.022 & 0.000 \\
Others i.e grass (1=yes) & & \\
Cooking fuel choices & 0.027 & 0.000 \\
Gas\& grid electricity (1=yes) & 0.058 & 0.000 \\
Kerosene \& charcoal (1=yes) & -0.102 & 0.000 \\
Fuel wood (1=yes) & 0.017 & 0.000 \\
Other fuel i.e. dung (1=yes) & \multicolumn{2}{c}{12,439} \\
Observations & \multicolumn{2}{c}{} \\
\hline
\end{tabular}

However, the IHS4 dataset did not allow to assess other purposes for energy utilization and also multiple fuel use which is termed as "fuel stacking" because the respondents were only asked to mention their main fuel sources for lighting and cooking in the homes. "Fuel stacking or energy transition" asserts that utilization of both clean and unclean energy fuel sources still occurs regardless of household high-income levels for various reasons (Heltberg, 2005; Masera et al., 2000). For this study, it was not possible to test the fuel stacking hypothesis since the IHS4 dataset did not capture information regarding primary and secondary fuels for lighting and cooking purpose except only for those that were connected to the national grid. Reasons for multiple fuel use by households in developing countries have been attributed not only to economic factors but other factors as well that are deeply connected to culture, the social make-up or indeed just to increase security of supply based on household needs (Mekonnen \& Kohlin, 2009; Pachauri \& Spreng, 2004).

As a result, binscatter plots were used to assess only the energy ladder hypothesis for the sampled households based on their energy security status (Martey, 2019; Cattaneo, 2019). The energy ladder hypothesis stipulates that households with low income level are likely to consume traditional fuels such as crop residues at the bottom of the ladder that are considered as "dirty" but as the income increases, the households are likely to move up the ladder by switching to transitional fuels such as charcoal or kerosene and finally to modern fuels such as gas and electricity as their income increases furthermore (Toole, 2015). Fig 4 and Fig 5 indicate the binscatter plots to show the relationship between the lighting and cooking fuel choices of the sampled households based on the energy insecurity status respectively. Firstly, the results from Fig.4 show that both the energy-secure and energyinsecure households seemed to have same relationship for all lighting fuels and household expenditure quintiles with exception of choice of other fuels such as grass. The energy-secure had an inverse relationship over the choice of other fuels whilst the energy-insecure showed a positive relationship with this type of fuel source.

Secondly, with regard to cooking fuels, Fig.5 showed that the energy secure were more likely to use more of modern fuels (gas, electricity) relative to the energy insecure as the income kept on rising. However, both the energy-secure and energy-insecure had similar positive relationship with transitional fuels (kerosene, charcoal) as their income increased. Lastly, the energy secure were less likely to use traditional fuels such as fuel wood or crop residues as their income increased. It was interesting to note that the energy insecure were also less likely to use fuel wood when their income rose. However, they seemed to have a constant relationship with use of other fuels such as crop residues and grass as their income rises. These findings resonate well with both current and old literature which show that energy insecurity is a complex issue because it intersects with other hardships such as food insecurity (Banash et al., 2013), water (Webber, 2016) and housing insecurity (Hernandez, 2013) coupled with other social burdens (Cook et al., 2008). Apart from energy choices and services other differences were observed in demographic variables (Table 4), geographical variables (Table 5), and housing, dwelling status and asset variables (Table 6). 

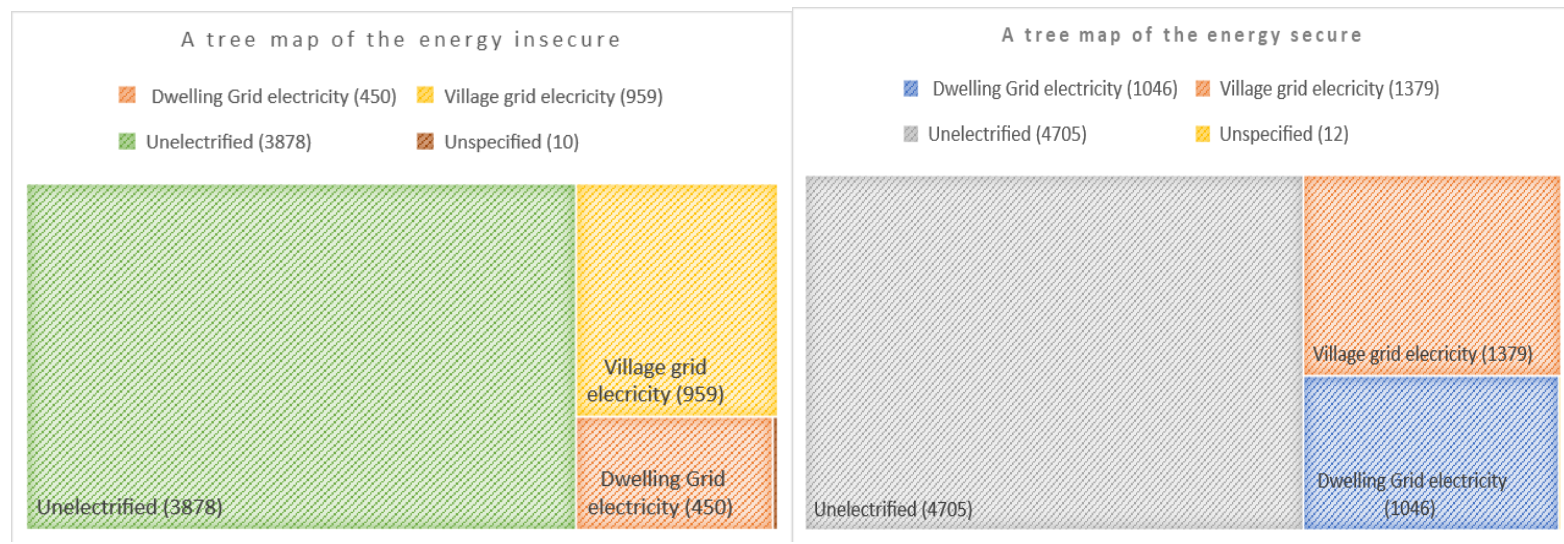

Fig. 2 A graphical representation of grid electricity connection, by energy insecurity status. (Source: Authors' estimates based on the data from IHS4 data, NSO, 2018)

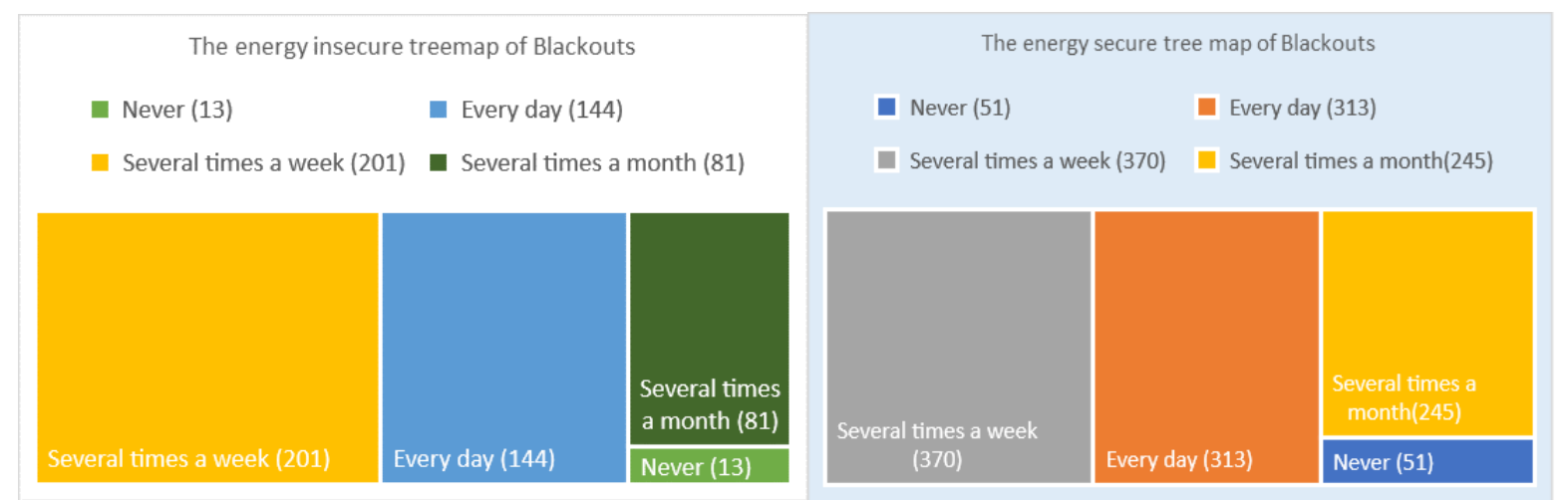

Fig. 3 A graphical representation of blackouts patterns, by energy insecurity status. (Source: Authors' estimates based on the data from IHS4 data, NSO, 2018)

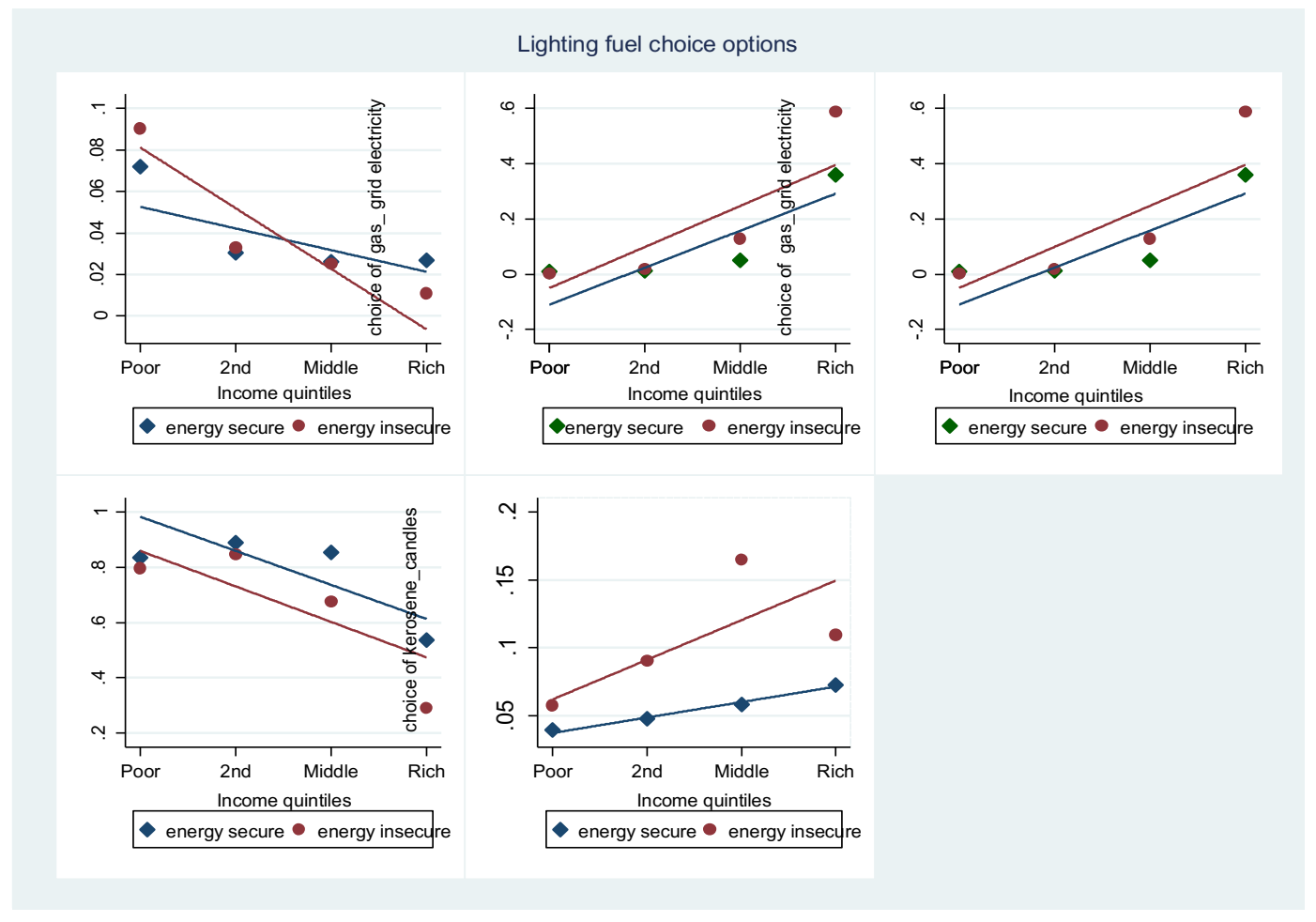

Fig.4 Lighting energy choice and Income by energy insecurity status 


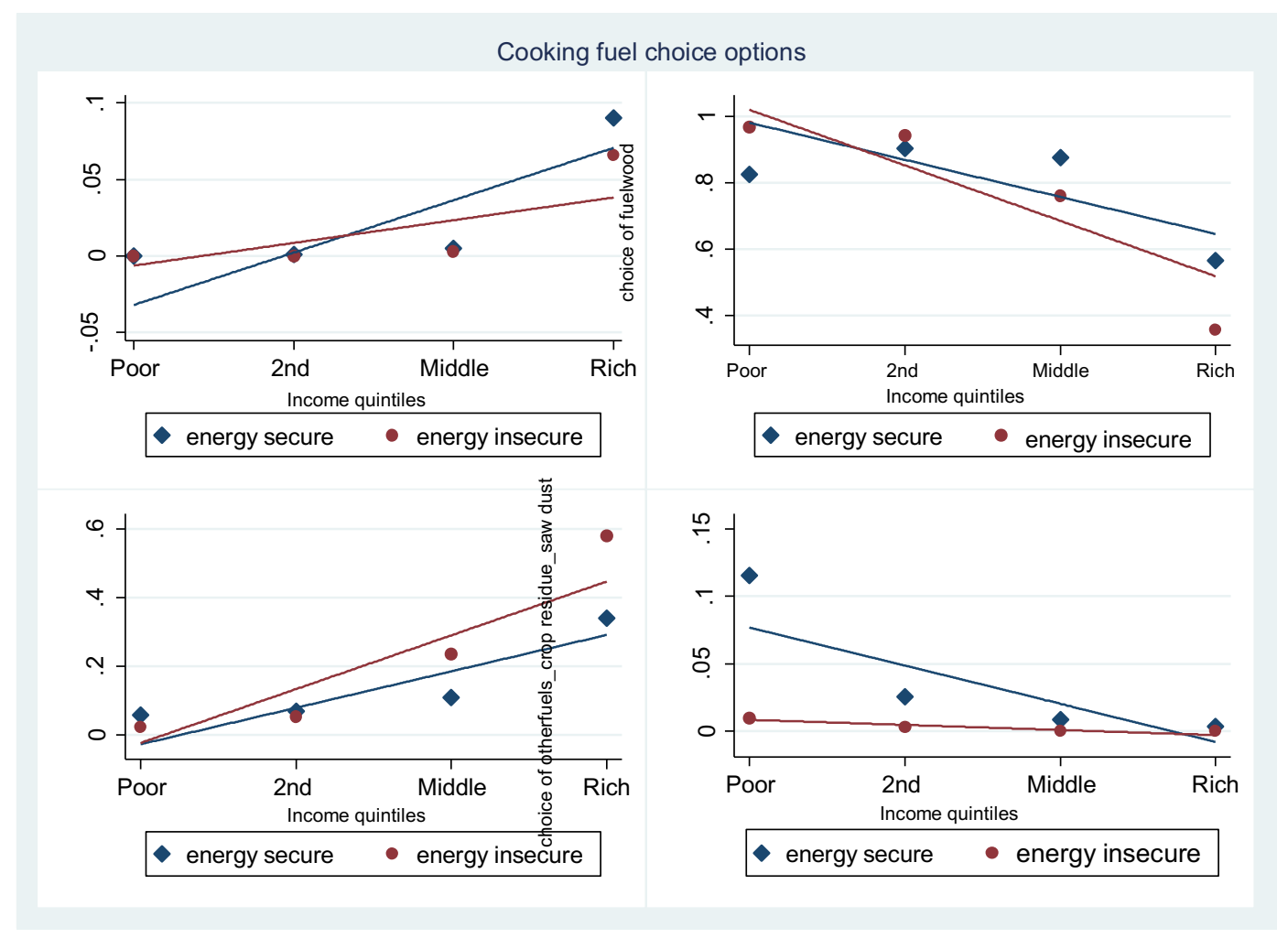

Fig.5 Cooking energy choice and Income by energy insecurity status

Table 4

Mean comparison for demographic variables

\begin{tabular}{|c|c|c|}
\hline \multirow{2}{*}{ Variable } & \multicolumn{2}{|c|}{ Difference in mean } \\
\hline & (energy secure)- (energy insecure) & $\mathrm{p}$-value of diff. \\
\hline Gender (1=male) & 0.113 & 0.000 \\
\hline Marital status of Household head (1=yes) & 0.142 & 0.000 \\
\hline Age (years) & -0.886 & 0.000 \\
\hline Household head with no education ( $1=$ yes) & -0.073 & 0.000 \\
\hline Household head with primary education ( $1=$ yes $)$ & 0.018 & 0.000 \\
\hline Household head with secondary education $(1=$ yes & 0.038 & 0.000 \\
\hline Household head with tertiary education $(1=$ yes $)$ & 0.016 & 0.000 \\
\hline Household size (number) & 0.994 & 0.000 \\
\hline Poverty status $(1=$ yes $)$ & -0.202 & 0.000 \\
\hline Children (number of those below 6 years) & 0.112 & 0.000 \\
\hline Elderly (number of those above 60 years) & -0.058 & 0.000 \\
\hline Total annual household expenditure per capita & 570122.4 & 0.000 \\
\hline Plot ownership (1=yes) & -0.039 & 0.000 \\
\hline Livestock ownership (1=yes) & 0.145 & 0.000 \\
\hline Share of energy expenditure & -9.290 & 0.000 \\
\hline Observations & \multicolumn{2}{|l|}{12,439} \\
\hline
\end{tabular}

Table 4 presents differences in means of the demographic variables of the sampled households based on energy insecurity status. The result shows that the groups were not balanced following the $\mathrm{P}$-value calculated using the Welch t-tests. In comparison to energy secure counterparts, the energy insecure on average were likely to be those advanced in age and less likely to be males
(Hernandez et al., 2016), elderly especially those above 60 years of age (Farbotko and Waitt, 2011), headed by those without formal education (Gonzalez-Eguino, 2015; Cook et al., 2008), more likely to be those who were poor in monetary terms (Hernandez, 2016), those who at least own a plot of land and finally those incurring a large share of energy expenses. Nevertheless, geographical and 
regional differences also play a big role. For instance, largest proportion of energy insecure households were found in the rural South (44\%) where Chiradzulo and Mangochi districts were mostly affected seconded by rural centre (33\%) where Lilongwe and Dedza districts were heavily affected as depicted in a Fig. 6 and Fig.7.

Fig. 7 which is a pareto chart provides a graphical display of Pareto which stipulates that when observing events, it is a phenomenon that $80 \%$ of events are due to $20 \%$ of the possible causes (Thiede et al., 2012). The Pareto Principle in which $\sim 20 \%$ of the problem referred to "vital few" in a population account for $\sim 80 \%$ of "useful many trivial" (the rest of the districts). Hence, Fig. 7 displays the frequencies of energy insecurity incidence in a descending order of observations, with bars depicting frequency in a given district whilst the line represents percentage of cumulative frequency (Jankowski et al., 2013).

The Pareto chart presents the findings from highest to lowest frequency for energy insecurity occurrences in this context. This type of analysis assists in indicating the few issues that cover the majority of the cases and the connected line represents the cumulative percentage line for the issue at hand. Pareto charts are used to choose the starting point for problem solving, monitoring changes, or identifying the basic cause of problem (Bednar et al., 2017).

Finally, Table 5 also reports the mean comparison for geographical variables of the sampled households based on their energy insecurity status. The results from welch t-tests revealed that there were indeed significant differences between the two groups attributed to geographical reasons or location. The Energy insecure were less likely to be found in urban areas and rural North. These results resonate with those study findings from Global North whereby spatial inequality and disparity in energy insecurity may exist between urban and rural areas due to limited access to modern energy sources such as gas or other electricity services that may easily be found in the urban communities (Jesse et al., 2019; Bednar et al., 2017).

Finally, Table 6 shows that there were also significant differences regarding housing, dwelling status and asset ownership amongst the sampled households after comparing the means using Welch t-tests based on their energy insecurity status because wealth inequality is becoming an issue of concern (Jesse et al., 2019).

Table 5

Means Comparisons for geographical variables

\begin{tabular}{lll}
\hline Variable & \multicolumn{2}{c}{ Difference in mean } \\
\cline { 2 - 3 } & $\begin{array}{l}\text { (energy secure)- } \\
\text { (energy insecure) }\end{array}$ & $\begin{array}{l}\text { p-value of } \\
\text { diff. }\end{array}$ \\
\hline Urban (1=yes) & 0.067 & 0.000 \\
Rural North (1=yes) & 0.122 & 0.000 \\
Rural Central (1=yes) & -0.092 & 0.000 \\
Rural South (1=yes) & -0.097 & 0.000 \\
Observations & \multicolumn{1}{c}{12,439} \\
\hline
\end{tabular}

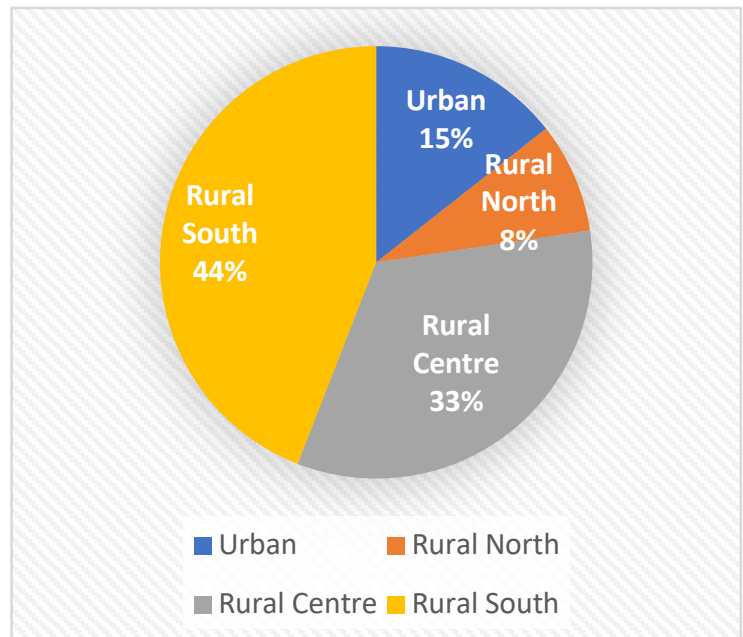

Fig.6 Regional distribution of energy insecurity incidence (\%)

The Energy-insecure were more likely to dwell in houses built with traditional materials, more likely to live in houses with grass thatched roofs and smoothed mud floor but less likely to be found in houses with burnt brick outer walls.

In terms of dwelling status, the energy insecure were less likely to be tenants but rather they were more likely to occupy houses in which they were either freely authorized to occupy or they occupy freely but not authorized to do so and not necessary being the actual owners. In addition, in terms of selected asset ownership, the energy insecure were less likely to own electrical gadgets such as refrigerator, TV, and fan. These results show that energy insecurity is influenced by housing tenure because renting, owning or free occupancy with or without authorization may result into unique problems that can escalate the energy insecurity challenge (Jesse $e t$ al., 2019; Martey, 2019). This depicts that the energy insecure might have more freedom to utilize any available energy sources with more free space without facing landlord restrictions as it is usually the case of those living in the rented homes (Bisu et al., 2016). Literature shows that poor tenants may have problems with house rents and may not afford to do efficiency upgrades set by landlords (Bird \& Hernandez, 2012). For Malawian case (or in the case of Malawi), this is different because, the energy insecure were found to occupy dwellings in which they were freely authorized or they occupied freely without authorization which meant there may be other factors as well. The energy-insecure were also less likely to own even solar panels which are renewable and alternative clean energy source. This finding is critical since adoption of solar home systems was attributed to high income levels that would allow household transition to solar energy use to take place (Lay et al., 2013). The results resonate with the findings of Middlemiss and Gillard (2015) who identified six challenges attributed to energy vulnerability namely; energy costs and supply issues, dwelling quality, household income stability, tenancy reasons, ill health and social relations. 
Citation: Mkomba-Khundi, F., Saha, A.K., and Wali,U.G. (2021) Household-level Effects of Energy Insecurity on Welfare in Southern Africa: A Malawian Case Study. Int. Journal of Renewable Energy Development, 10(1), 105-118, doi: 10.14710/ijred.2021.33234

$\mathrm{P}$ a g e | 114

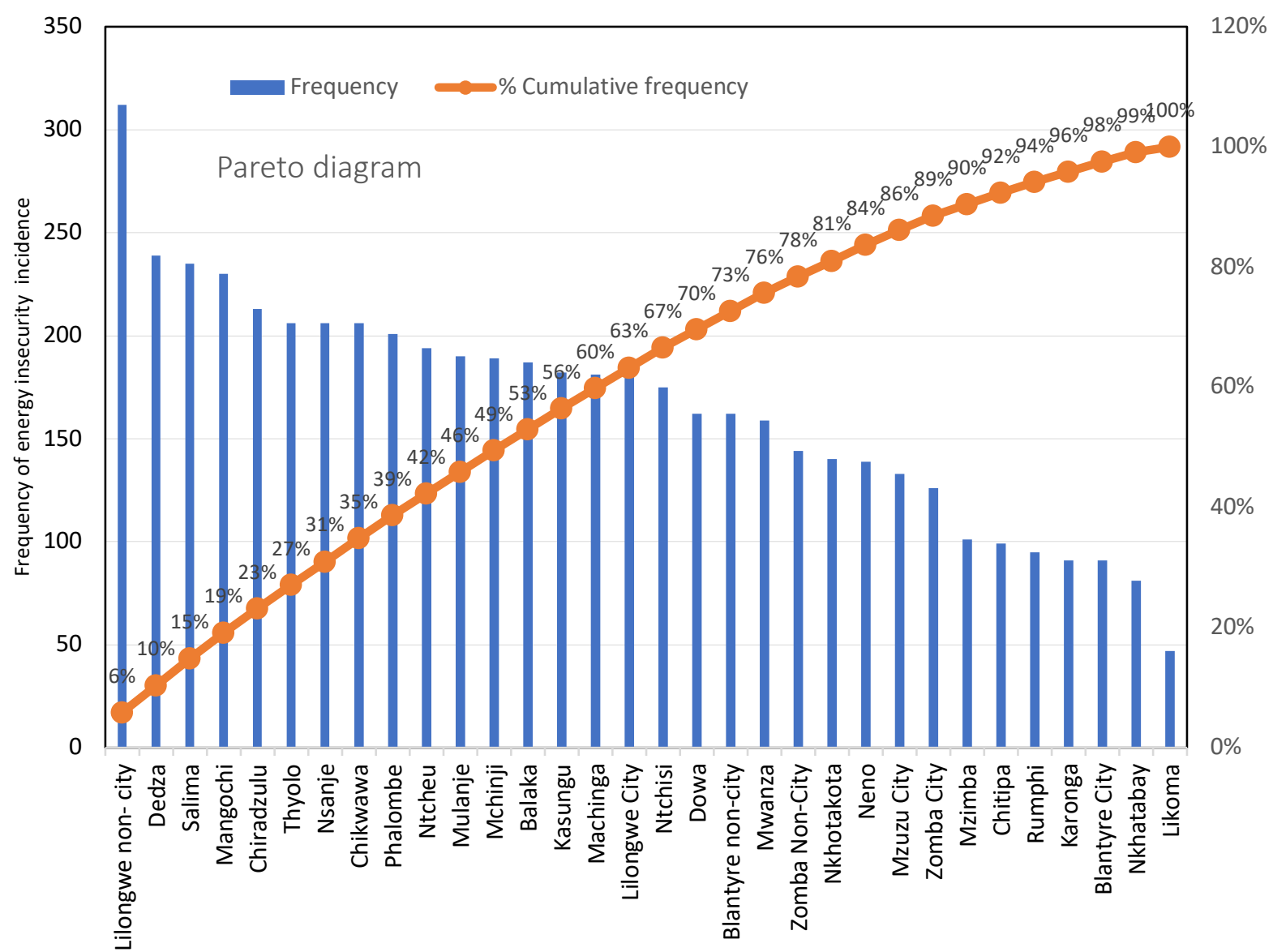

Fig.7. Distribution of energy insecurity incidences in malawian districts for the year 2016/17

Table 6

Means Comparisons for housing, dwelling status, and asset variables

\begin{tabular}{lll}
\hline Variable & Difference in mean & p-value of diff. \\
\cline { 2 - 3 } & (energysecure) (energyinsecure) & 0.111 \\
\hline Dwelling status as owner occupant (1=yes) & -0.012 & 0.000 \\
Dwelling status as free but authorized or free not authorized (1=yes) & -0.039 & 0.000 \\
Dwelling status as tenant occupant (1=yes) & 0.038 & 0.000 \\
Traditional latrine with roof (1=yes) & 0.048 & 0.000 \\
Number of sleeping rooms & 0.425 & 0.000 \\
Routine home maintenance & 12363.56 & 0.000 \\
Expenditure on actual rents & 4491.88 & 0.000 \\
Dwelling with traditional construction material (1=yes) & -0.163 & 0.000 \\
Grass thatched roof (1=yes) & -0.166 & 0.000 \\
Smoothed mud floor (1=yes) & -0.135 & 0.000 \\
Burnt brick outer wall (1=yes) & 0.143 & 0.000 \\
Own TV (1=yes) & 0.089 & 0.000 \\
Own Satellite dish (1=yes) & 0.044 & 0.000 \\
Own electric or gas stove (1=yes) & 0.042 & 0.000 \\
Own iron for pressing clothes (1=yes) & 0.115 & 0.000 \\
Own refrigerator (1=yes) & 0.048 & 0.000 \\
Own Solar panel (1=yes) & 0.045 & 0.000 \\
Own fan (1=yes) & 0.038 & 0.000 \\
Own Satellite dish (1=yes) & 0.044 & \\
Observations & 12,439 &
\end{tabular}




\subsection{To what extent does energy insecurity incidence affect household welfare?}

The main hypothesis for this paper was to assess how household energy insecurity impacts household welfare (food and education consumption). The analytical technique involved estimating multiple regression models (Model 1 and Model 2). The results from these models are presented in Tables 7 and 8. The regression results from Model 1 in Table 7 showed that household energy insecurity decreased household food consumption by $17 \%$ in reference to those that were energy secure. Similarly, a closer look at the household education outcome (Table 8) indicates that those that were energy insecure at household level experienced a large decrease of approximately $33.4 \%$ in its education consumption compared to the energy secure households. This finding shows that energy security plays a key role towards improvement of household welfare in general as it largely affects household consumption of the basic necessities.

In order to get a thorough understanding in terms of magnitude of the effect of energy insecurity on household welfare the study further looked at proportion of energy expenditure to the total expenditure. The regression results from model 2 (Table 7) indicate that energyinsecure households were likely to reduce expenses on food consumption approximately by $2.3 \%$ for each $1 \%$ unit increase in energy expenditure proportional to total household expenditure. As for the education outcome, Table 8 shows that energy-insecure households were likely to reduce education expenditure by $3.6 \%$ for each $1 \%$ unit increase in energy expenditure proportional to total household expenditure. This implied that food and education expenses were likely to be affected by each proportion set aside for energy expenditure at household level.

Regarding other socio-economic characteristics that had displayed large effects on the household welfare. Considering the food consumption, household income level "proxied' by log per capita consumption had positive influence on food consumption by $81 \%$. Others that positively affected food consumption were marital status (23\% increase); plot ownership (4\% increase), livestock ownership ( $2 \%$ increase) and owner occupants (2\% increase). These findings suggest the need to explore installation of biogas plants as renewable energy source especially to those who own livestock and plots following an Ethiopian case study that showed economic benefit in form of money savings from fuel expenses and income generation through selling slurry that replace chemical fertilizer (Alemayehu, 2015). On the other hand, some of the factors that had negative influence on food consumption were drinking water access (5\% decrease); education level of household head (4\% decrease).

As for education outcome, some of the factors that positively affected it were grid electricity access (37\% increase), log per capita consumption (58\% increase), urban location (62\% increase), plot ownership (36.6\% increase), livestock ownership ( $42.6 \%$ increase). Those factors that showed negative influence on education consumption included: gender of household and marital status of household head (65.8\% decrease).

Table 7

Regression coefficient estimates of log of household food consumption

\begin{tabular}{lcc}
\multicolumn{1}{c}{ Covariate } & Model 1* & Model 2 $^{\dagger}$ \\
\hline Urban location & -0.007 & -0.001 \\
Education of household head & $(0.011)$ & $-0.011)$ \\
Main source of drinking water & $-0.038(0.010)^{* * *}$ & $-0.059(0.009)^{* * *}$ \\
Gender of Household head & $-0.048(0.012)^{* * *}$ & $-0.141(0.011)^{* * * *}$ \\
Age of Household head & $-0.152(0.012)^{* * *}$ & $-0.001(0.000)^{* * *}$ \\
Household size & $-0.001(0.000)^{* * *}$ & $0.219(0.003)^{* * *}$ \\
Household Energy insecurity status & $0.233(0.003)^{* * *}$ & excluded \\
Share of energy expenditure & $-0.173(0.007)^{* * *}$ & -0.023 \\
Marital status of Household head & Excluded & $(0.001)^{* * *}$ \\
Tenancy & $0.229(0.012)^{* * *}$ & $0.209(0.011)^{* * *}$ \\
Plot ownership & 0.000 & -0.006 \\
Livestock ownership & $(0.013)$ & $(0.013)$ \\
Owner occupant & $0.041(0.008)^{* * *}$ & $0.041(0.008)^{* * * *}$ \\
Log per capita consumption & $0.019(0.006)^{* * *}$ & 0.013 \\
Grid electricity access & 0.018 & $(0.006)^{* * *}$ \\
Constant & $(0.008)^{* *}$ & 0.017 \\
\hline
\end{tabular}

Measure of goodness of fit. Number of obs=12,438; F (14, 12423) $=1818.66$; Prob > F=0.0000; R-squared=0.7822 Root MSE=0.3196.

Note: ${ }^{* * *}$ ( $1 \%$ level of statistical significance); ${ }^{* *}(5 \%$ level of statistical significance); * (10\% level of statistical significance)

\footnotetext{
"Multiple regression model (Model 1) used Robust Standard Error Correction and excluded 'share of energy expenditure to total expenditure as a regressor.

‘Multiple regression model (Model 2) used Robust Standard Error Correction and excluded 'energy insecurity status' as a regressor.
} 

Energy Development, 10(1), 105-118, doi: 10.14710/ijred.2021.33234

$\mathrm{P}$ a g e | 116

Table 8

Regression coefficient estimates of log of household education expenditure

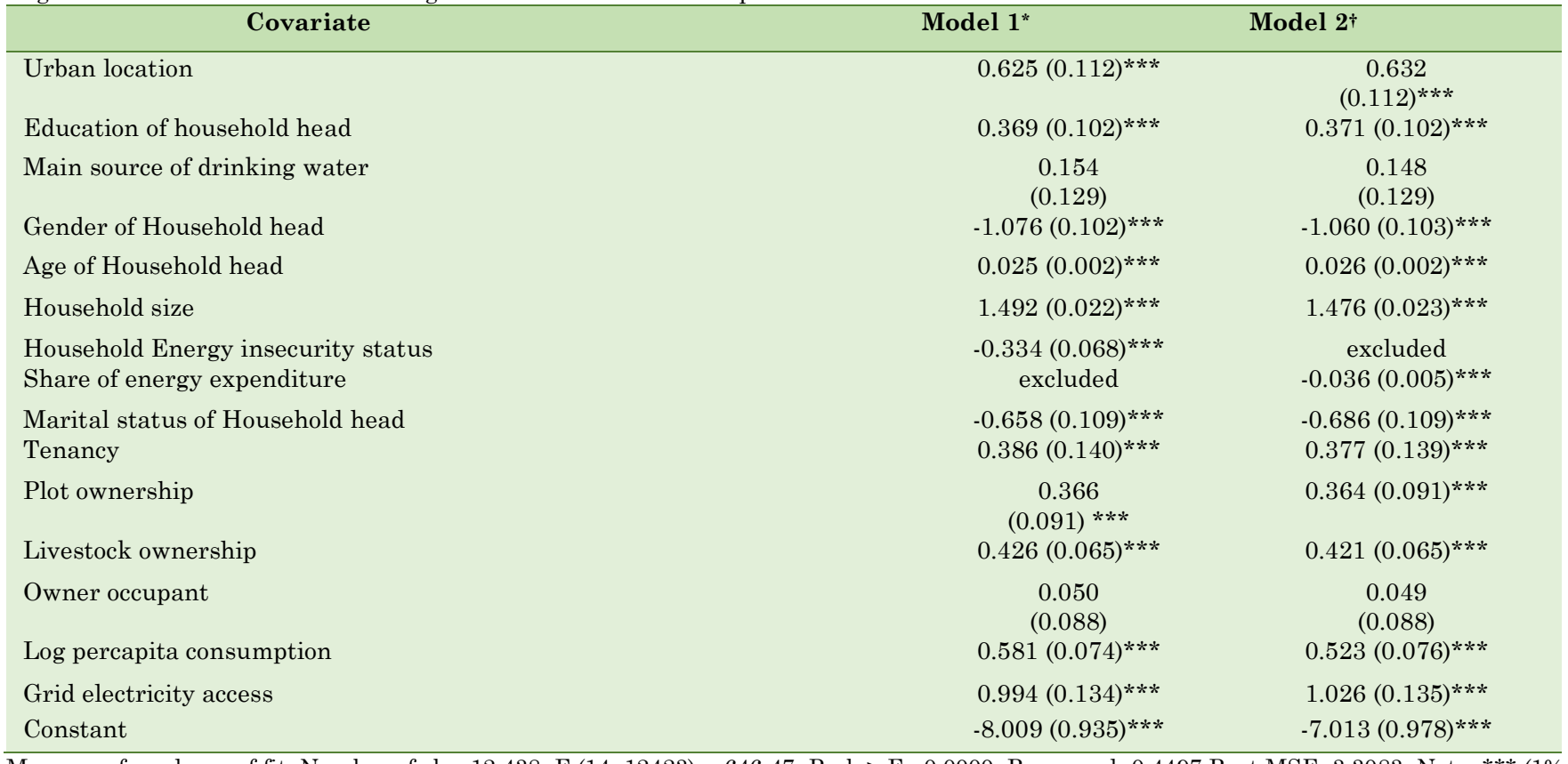

Measure of goodness of fit. Number of obs=12,438; F $(14,12423)=646.47 ;$ Prob $>$ F $=0.0000 ;$ R-squared=0.4497 Root MSE=3.3083. Note: $* * *(1 \%$ level of statistical significance); ${ }^{* *}(5 \%$ level of statistical significance); * $(10 \%$ level of statistical significance

\subsection{Policy recommendations}

The policy implications from this study are threefold. Firstly, the government together with electricity companies to upscale and increase beneficiary targeting of the Malawi rural electrification programme to increase electricity access, taking into consideration geographical and resource factors. In addition, the government needs to engage in public information and demonstration campaigns to raise consumer awareness on availability of affordable, modern and sustainable energy products.

Secondly, the government of Malawi needs to encourage the existing electricity companies to quickly adopt and implement vibrant demand side management program that will aim at ensuring not only energy efficiency but also energy savings through popularization of solar for lighting, LPG and certified improved cook stoves so that consumers are stress-free from bill payments and overburdened utility systems. The option for solar can be achieved through "Pay as You Go" scheme. Suffice to say that majority of Malawian households rely on biomass fuel and are skeptical to use LPG and certified cook stoves due to safety concerns and low technical knowledge (Practical Action, 2017; Maganga et al., 2015).

Finally, there is need to introduce and pilot a special energy security scheme that can target the elderly and female headed households for both the rural and urban poor so that they are cushioned especially now with the coming of the Corona virus/COVID-19 pandemic.

\section{Conclusion}

The objectives of this research study were to characterize the households which face energy insecurity and also analyze the effect of energy insecurity on household welfare (food and education consumption outcomes) in Malawi. Using nationally representative sample dataset and from Global South context under a micro-economic perspective, this study revealed that the energy-insecure are a heterogenous group who differ from their energysecure counterparts in terms of demographics; socioeconomic status; household energy use patterns; housing and dwelling status; and geographical location. Additional results from econometric analysis showed that energy insecurity decreased household food consumption and education expenditures.

\section{References}

Aberman, N.L., Meerman, J. \& Benson, T. (2018) Agriculture, Food Security, and Nutrition in Malawi: Leveraging the links. International Food Policy Research Institute. Washington DC.

Ahmad, N.A. \& Byrd, H. (2013). Empowering Distributed Solar PV Energy for Malaysian Rural Housing: Towards Energy Security and Equitability of Rural Communities. Int. Journal of Renewable Energy Development, 2(1),59-68.

Alemayehu, Y.A (2015). Status and Benefits of Renewable Energy Technologies in the Rural Areas of Ethiopia: A Case study on Improved Cooking Stoves and Biogas Technologies. Int. Journal of Renewable Energy Development,4(2), 103111.http://dx.doi.org/10.14710/ijred.4.2.103-111.

\footnotetext{
* Multiple regression model (Model 1) used Robust Standard Error Correction and excluded 'share of energy expenditure to total expenditure as a regressor.

$†$ Multiple regression model (Model 2) used Robust Standard Error Correction and excluded 'energy insecurity status' as a regressor.
} 
Ayoo, C. (2020). Towards Energy Security for the Twenty-First Century, Energy Policy, Tolga Taner, IntechOpen, DOI: 10.5772/intechopen.90872. Available from: https:// www.intechopen.com/books/energy-policy/towards-energysecurity-for-the-twenty-first-century

Banash, A.K.,Holben, D.H.,\& Basta, T.(2013) Food insecurity is associated with household utility insecurity among individuals living with HIV/AIDS in rural Appalachia. $J$ Hunger Environ Nutr. (20130 8:242-55.

Barnes,D.F., Khandker, S.R,\& Samad, H.A. (2010). Energy Access, Efficiency, and Poverty: How many are energy poor in Bangladesh? Policy Research Working Paper 5332. The World Bank. June 2010.

Bednar,.D.J., Reames,.T.G., Keoleaian, G.A. (2017). The intersection of energy and justice: modelling the spatial, racial/ethnic and socioeconomic patterns of urban residential heating consumption and efficiency in Detroit, Michigan. Energy Build. (2017) 143:25-34.

Berry, C., Hronis, C.\&Wood ward, M. (2018). "Who 's Energy Insecure? You Might be Surprised." 2018 ACEEE Summer study on Energy Efficiency in Buildings: Making Efficiency Easy and Enticing. https: aceee.org/files/proceedings/2018/index.html\#/paper/eventdata/p393.

Bird, S. \& Hernandez, D. (2012). Policy options for the split incentive: Increasing energy efficiency for low income renters. Energy policy (2012) 48: 506-14.doi: 10.1016/j.enpol.2012.05.053.

Bisu, D.Y., Kuhe, A., \&Lortyer, H.A. (2016). Urban household cooking energy choice: an example of Bauchi metropolis, Nigeria. Energy, Sustainability and Society, 6, 15. DOI 10.1186/s13705-016-0080-1.

Brown, M. A, Soni, A., Lapsa, M. V., Southworth, K. 2020. Low Income Energy Affordability: Conclusions from a Literature Review. Energy and Transport Science Division. OAK Ridge National Laboratory. US department of Energy. USA. ORNL/TM-2019/1150.

Castro-Sitiriche, M.J\& Ozik, J. 2014. Rural Electrification Pathways to Well-being. Conference paper presented at 6th International Conference on Appropriate Technology. Kenyatta University Conference Center. November 2014, Nairobi, Kenya.

Cattaneo, M. D., R. K. Crump, M. H. Farrell, \&Feng, Y. (2019). Binscatter Regressions," in preparation for the Stata Journal. Department of Economics and Department of Statistics, University of Michigan.

Cobb, C.W., \&Douglas, P.H. (1928). A theory of production. American Economic Review 1928;18 (supplement):139-65.

Cook,J. \& Shah, M. (2018a). Reducing Energy Burden with Solar: Colorado's Strategy and Roadmap for States. National Renewable Energy Laboratory. NREL/TP-6A20-70965. https://www.osti.gov/biblio/1431421.

Cook, J.T, Frank, D.A., Casey, P.H., Rose -Jacobs, R., Black, M.M., \&Chilton, M. (2008) A brief indicator of household energy security: associations with food security, child health, and child development in US infants and toddlers. Pediatrics. (2008) 122: e867-75.

Colton, R.D. (2011). "Home Energy Affordability in New York: The Affordability gap (2008-2010)." Prepared for New York State Energy Research Development Authority (NYSERDA) Albany, New York.http://www.nyserda.ny.gov//media/Files/EDPPP/LIFE/Resources/2008-2010affordability-gap.pdf.

Chikhungu, Lana Clara, Nyovani Janet Madise, \& Sabu S. Padmadas. (2014). How Important are Community Characteristics in Influencing Children's Nutritional Status? Evidence from Malawi Population-based Household and Community Surveys. Health and Place 30, 187-195.

Culver, L (2017).'Energy Poverty; What you measure matters,' in Proceedings of the Reducing Energy Poverty with Natural gas: Changing Political, Business and Technology Paradigms Symposium, Stanford, CA, USA, pp.9-10.

Drehobl, A.,\&Ross, L. (2016). Lifting the High Energy Burden in America's Largest Cities: How Energy Efficiency can improve Low Income and Undeserved Communities. Report by Energy Efficiency for All and the American Council for an EnergyEfficiency Economy.

Elnakat, A., J.D. Gomez, and N. Booth. (2016). A zip code study of socioeconomic, demographic, and household gendered influence on the residential energy sector. Energy Reports 2, 21-27. https://doi.org/10.1016/j.egyr.2016.01.003.

Ezema, I.C., Olotuah, A. O., \& Fagbenie, O.I.S. (2016). Evaluation of energy use in public housing in Lagos, Nigeria: Prospects for Renewable Energy Sources. Int. Journal of Renewable Energy Development, 5(1) 15-24. http://dx.doi.org|10.14710|ijred.5.1.15-24.

Fang, Y.(2011). Economic welfare impacts from renewable energy consumption: The China experience. Renewable \&Sustainable Energy Reviews 15 :5120-5128.

Farbotko C,\&Waitt, G.(2011). Residential air conditioning and climate change: voices of the vulnerable. Health Promotion $J$ Aust. (2011) 22:13-5.

Foster, V., Jean-Phillipe. \& Wodon, Q. (2000).Energy Prices, Energy efficiency, and Fuel Poverty Latin America and Caribbean Regional Studies Programme. World Bank, Washington DC.USA.

Gonzalez-Eguino, M.(2015). Energy Poverty: An Overview. Renew Sustain Energy Rev. (2015) 47:377-85.

Government of Malawi (2017). Support to SE4ALL Country Actions processes in Malawi. Action Agenda.

Government of Malawi (2018). National Energy Policy. Ministry of Natural Resources, Energy and Mining. Capital Hill. Lilongwe 3. Malawi.

Groh, S., Pachauri,S., \&Rao, N.R. (2016). 'What are we measuring? An empirical analysis of household electricity access metrics in rural Bangladesh,' Energy for sustainable development 30: 21-31.

Handsaker M.I, \& Douglas P.H. (1937). The Theory of marginal productivity tested by data for manufacturing in Victoria. Quarterly Journal of Economics 52:1-36.

Heltberg, R. (2005). Factors determining household fuel choice in Guatemala. Environment and Development Economics 10 (2005) pages 337-361. https: //doi.org/10.1017/S1355770X0 4001858.

Hernandez, D.,Jiang, Y.,Carrion, D., Phillips, D., \& Aratani, Y. (2016).Housing hardship and energy insecurity among native-born and immigrant low-income families with children in the United States, Journal of Children and Poverty, DOI:10.1080/10796126.2016.1148672.

Hernández., Aratani, Y.,\& Jiang, Y. (2014). Energy Insecurity among families with children. New York: National Center for Children in Poverty, Columbia University Mailman School of Public Health.

Hernandez, D. (2013). Energy insecurity: A framework for understanding energy, the built environment, and health among the vulnerable populations in the context of climate change. Am J Public Health. (2013) 103: e 32-4.

Hernandez, D. (2016). Understanding "energy insecurity" and why it matters to health. Social Sci Med. (2016) 167:1-10.

Jankowski, M.D.,Williams, C.J., Jeanne, M.F.\&Owen, J.C. (2013). Birds Shed RNA-Viruses According to the Pareto Principle. PloS ONE 8 (8).

Jessel S, Sawyer, S., \& Hernandez, D. (2019). Energy, Poverty, and Health in Climate Change: A Comprehensive Review of an Emerging Literature. Front. Public Health 7: 357.doi:10.3389/fpubh.2019.000357.

Lay J, Ondraczek J,\& Stoever J. (2013). Renewables in theenergy transition: Evidence on solar home systems and lighting fuel choice in Kenya. Energy Econ. 40: 350-359.

Long,L.K., Hui, L.C.,Fook, G.Y., Nazmee, \& Zainon, W.M.N.W.(2017) A study on the effectiveness of Tree-Maps as 
Tree Visualization Techniques.Procedia Computer Science 124 (2017) 108-115.

Lopez-Espin,J.J., Vidal, A.M., \&Gimenez, D. (2012). Two stage least squares and indirect least squares algorithms for simultaneous equations models. Journal of Computational and Applied Mathematics 236, 3676-3684.

Lv, Y., Si, C., \& Zhang, S. (2018). Impact of Urbanization on energy intensity by adopting a new technique for regional division: Evidence from China. Environ Sci Pollut Res 25, 36102-36116 (2018). https://doi.org/10.1007/s11356-018-34121.

Manda, M.A.Z. (2013). Situation of Urbanization in Malawi Report. Malawi Government, Ministry of Lands and Housing.

Maganga, M.A., Maonga, B.B. \& Gebremariam, G.G. (2015). Non-price determinants of household's choice of cooking energy in Malawi. International Journal of Development and Sustainability, 4 (1), 18-28.

Masera, O. R., Saatkamp, B. D., \&Kammen, D. M. (2000). From linear fuel switching to multiple strategies: a critique and alternative to the energy ladder model. World Development 28, 2083-2103.

Martey, E. (2019).Tenancy and energy choice for lighting and cooking: Evidence from Ghana. Energy Economics 80, 570-581.

Mango, N., Makate, C., Mapemba, L., Sopo, M. (2018). The role of crop diversification in improving household food security in Central Malawi. Agri \& Food secur.7. https://doi.org/10.1186/540066-018$0160-\mathrm{y}$.

Maxim, A., Mihai, C., Apostoie, C.M., Popescu, C., Istrate,C., $\&$ Bostan, I. (2016). Implications and measurement of energy poverty across the European Union. Sustainability 8 (5), 483. 2016. https://doi:10.3390/su8050483.

Mekonnen, A., \&Kohlin, G. (2009). Determinants of household fuel choice in major cities in Ethiopia. Working papers in economics No. 399 (2009).

Middlemiss, L. \& Gillard, R. (2015). Fuel Poverty from the bottom-up: Characterizing household energy vulnerability through the lived experience of the fuel poor. Energy Research \& Social Science 6, 146-154

Mirza, B. \& Szirmai,A. (2010). Towards a new measurement of energy poverty: A cross community analysis of rural Pakistan' UNU-MERTI Working Papers, No.024.

Moore, R., (2012). Definitions of Fuel poverty: Implications for Policy. Energy Policy 49,19-26.

National Statistics Office (2018). Malawi Integrated Household Survey 2016-2017. Household Socioeconomic Characteristics report. Republic of Malawi.

National Statistics Office (2019). 2018 Malawi Population and Housing Census Report. Zomba. Malawi.

Nguyen, H. M\& Nguyen, T.A., (2019). Investigating the determinants of household welfare in the Central Highland, Vietnam.

Nussbaumer, P., Bazilian, M.,\& Modi, V. (2012). Measuring energy poverty: focusing on what matters. Renew. Sustain. Energy Rev.16,231-243

Pachauri, S., \&Spreng, D. (2004). Energy use and energy access in relation to poverty. Economic and Political Weekly 39 (3), 271-278.

Pachauri, S., \&Spreng,D. (2011). Measuring and monitoring energy poverty. Energy Policy, doi: 10.1016/j.enpol.2011.07.008.
Phoumin, H., \& Kimura, F. (2019). Cambodia's energy poverty and its effects on social well-being; Empirical evidence and policy implications. Energy policy 132, 283-289.

Phoumin, H.,\& Kimura, F. (2019). The impacts of energy insecurity on household welfare in Cambodia: Empirical evidence and policy implications. Economic Modelling, https://doi.org/10.1016/j.econmod.2019.09.024.

Practical Action (2017). Final Quantitative Report on the Cost and Efficiency of Cooking Fuels in Malawi. Practical Action Consulting. Lilongwe. Malawi.

Pye, S., Dobbins, A., Baffert, C., Brajkovic, J., Grgurev, I., De Miglio, R.,\&Deane, P. (2015). Energy Poverty and Vulnerable Consumers in the Energy Sector across the EU:Analysis of Policies and Measures. INSIGHT_E. https://ec.europa.eu/energy/sites/ener/files/documents/INSIG HT_E_Energy\%20Poverty\%20\%20Main\%20Reportר_FINAL.pdf, Accessed date :11 August 2020

Ross, L., Drehobl, A. \&Stickles, B. (2018). "The High Cost of Energy in Rural America: Household Energy Burdens and Opportunities for Energy Efficiency." ACEEE Research Report U1806.https://aceee.org/research-report/u1806.

Khandker, S., Barnes, D.,\& Hussain, A.S. (2012). Are the energy poor also income poor? Evidence from India. Energy policy 47, 1-12 2012.

Shoaib, A., \&Ariaratnam, S. (2016). A study of Socioeconomic Impacts of Renewable Energy Projects in Afghanistan. Procedia Engineering 145, 995-1003.

Stringer, L.C., Dyer, J.C., Reed, M.S., Dougill, A.J., Twyman,C.,\& Mkwambisi, D.(2009). Adaptions to Climate change, Drought, and Desertification: Local insights to Enhance Policy in Southern Africa." Environmental Science \& Policy $12,748-765$.

Thiede, S., Bogdanski,G.,\&Hermann, C. (2012). A systematic method for increasing the energy and resource efficiency in manufacturing companies. Procedia CIRP 2 (2012) 28-33.

Toole, R. (2015). The Energy Ladder: A Valid Model for Household Fuel Transitions in Sub-Saharan Africa? Master's thesis 2015.

Tchereni, B.H.M. (2013). An Econometric Analysis of Energy Poverty and Sustainable Development in Blantyre (Malawi). $\mathrm{PhD}$ Thesis. North-West University.

Thomson, H., Bouzarovski, S., \&Snell, C. (2017). Rethinking the measurement of energy poverty in Europe. Indoor Built Environ.26 (2017) 879-901.

United Nations Development Programme (2017). The Sustainable Development Goals Report.UN, New York. USA.

Webber,M.E. Thirst for Power: Energy, Water, and Human Survival. Danbury, CT: Yale University Press (2016).

William, J. (1945).Professor Douglas' production function. Economic Record 25:55-64.

World Bank (2016). Malawi Urbanization Review: Leveraging Urbanization for National Growth and Development.

Zou, B. \& Luo, B. (2019). Rural household energy consumption characteristics and determinants in China. Energy 182, 814823. 